\title{
Is Continuous Glucose Monitoring Underappreciated in the UK?
}

\author{
Christopher G Parkin, ${ }^{1}$ Melissa Holloway, ${ }^{2}$ Jeffrey Truesdell ${ }^{3}$ and Tomas C Walker ${ }^{3}$ \\ 1. CGParkin Communications, Inc., Boulder City, NV, US; 2. Speaking Diabetes Ltd, London, UK; 3. Dexcom, InC., San Diego, CA, US
}

DOI: https://doi.org/10.17925/EE.2017.13.02.76

\begin{abstract}
ntroduction: Information about continuous glucose monitoring (CGM) use in the UK is limited. We conducted an online survey of a representative sample of current CGM users in England, Scotland and Wales to address this deficit. Methods: The 29-item online survey was conducted between 29 December 2016 and 25 January 2017. Persons with type 1 diabetes (T1D) and caregivers of T1D children/ adolescents were recruited from mailing lists, using Nielsen and Harris Polling databases. Results: 315 patients and caregivers responded to the survey - 170 adult patients and 145 caregivers. Among respondents, 144 received full funding for CGM use, 72 received partial funding and 83 received no funding. Most reported improvements in glycated haemoglobin (HbA1c) (67.0\%), fewer hypoglycaemia episodes (70.2\%), improved hypoglycaemia awareness (77.5\%) and better diabetes management (92.4\%). Self-funders reported significantly higher CGM use (76.1\%) than those who were fully funded (58.9\%) and/or partially funded (65.9\%), $\mathrm{p}=0.0008$. Fewer than $50 \%$ of all respondents reported receiving guidance in interpreting CGM data from their diabetes care team; 30.1\% of self-funders reported receiving no CGM support from their diabetes team compared with fully funded (2.8\%) and partially funded (1.4\%) respondents, p<0.0001. Conclusions: Patients with T1D and their caregivers are realising benefits from CGM use but are largely unsupported by the UK healthcare system.
\end{abstract}

\section{Keywords}

Continuous glucose monitoring (CGM), insulin, multiple daily insulin injections (MDI), type 1 diabetes, selfmonitoring of blood glucose (SMBG)

Disclosure: Christopher G Parkin has received consulting fees from CeQur, Dexcom, Inc., Insulet, Mannkind, Roche Diabetes Care and Senseonics. Melissa Holloway is Chief Adviser of INPUT Patient Advocacy and has received

consulting fees from Dexcom, Inc. and Ascensia Diabetes Care UK Limited. Jeffrey Truesdell and Tomas C Walker are employees of Dexcom, Inc. Dexcom, Inc., provided funding for the development of this manuscript.

Compliance with Ethics: All procedures were followed in accordance with the responsible committee on human experimentation and with the Helsinki Declaration of 1975 and subsequent revisions.

Authorship: All named authors meet the International Committee of Medical Journal Editors (ICMJE) criteria for authorship of this manuscript, take responsibility for the integrity of the work as a whole, and have given final approval to the version to be published.

open Access: This article is published under the Creative Commons Attribution Noncommercial License, which permits any non-commercial use, distribution, adaptation and reproduction provided the original author(s) and source are given appropriate credit.

Received: 29 June 2017

Accepted: 2 August 2017

Citation: European Endocrinology, 2017;13(2):76-80

Corresponding Author: Christopher G Parkin,

CGParkin Communications, Inc., Boulder

City, NV, US. E: chris@cgparkin.org

Support: The publication of this article was supported by Dexcom, Inc. The views and opinions expressed are those of the authors and do not necessarily reflect those of Dexcom, Inc.
It is well known that optimising glycaemic control reduces the development and/or progression of microvascular and macrovascular disease in type 1 diabetes (T1D). ${ }^{12}$ Unfortunately, a significant percentage of individuals with diabetes are not achieving their recommended glycated haemoglobin ( $\mathrm{HbA1C}$ ) goals. ${ }^{3}$ Although achieving and maintaining optimal glycaemic levels through self-management remains a challenge for all individuals with T1D, regardless of geographic location, the quality of care and support patients receive is also a factor, which appears to differ from country to country.

It is estimated that up to $74 \%$ of adults with T1D in the UK have HbA1C levels $>7.5 \%,{ }^{4}$ which is in stark contrast to other Western countries. A comparison of glycaemic control between countries showed notable differences in median HbA1C levels in the UK, US and Germany among adults aged $\geq 25$ years $^{3}$ (Figure $1 A$ ). Similar differences in glycaemic control are observed among children/adolescents $<18$ years enrolled in the UK National Paediatric Diabetes Audit (NPDA), the US T1D Exchange (T1DX) and the Austrian/German Prospective Diabetes Follow-up Registry (DPV) ${ }^{5}$ (Figure 1B).

The past decade has seen significant advancements in diabetes management tools and technologies that have been demonstrated to improve glycaemic control in individuals with T1D. Real-time continuous glucose monitoring (rtCGM) is one such tool. Numerous studies have shown that use of rtCGM confers significant benefits on individuals with T1D using the technology, including improvements in $\mathrm{HbA} 1 \mathrm{c}$ and reductions in the occurrence of severe hypoglycaemia and/ or duration of hypoglycaemia. ${ }^{6-22}$

Although the majority of previous studies have been conducted among patients who use CGM in conjunction with insulin pump therapy, ${ }_{1}^{6-11}$ recent randomised clinical trials have demonstrated that patients using multiple daily insulin injections (MDI) can safely use CGM to reduce $\mathrm{HbA} 1 \mathrm{C}$, reduce hypoglycaemia and replace fingerstick testing for routine diabetes care decisions. ${ }^{21-26}$ Regardless of the method of insulin delivery, the benefit of CGM is primarily seen in patients who regularly use their devices at least $70 \%$ of the time..$^{6,12,21,22}$

Use of CGM has increased significantly in the US, particularly over the last 4 years, ${ }^{27}$ but adoption of this technology has been relatively slow in Europe due to lack of reimbursement, lack of awareness regarding the benefits of CGM and/or pursuit of cost containment. However, in 2016 German 
insurance payers decided to provide coverage for CGM use for all patients using intensive insulin therapy. ${ }^{28}$ While firm data on the increased adoption of CGM in Germany remain to be reported, anecdotal evidence suggests that there have been significant increases in the number of patients benefitting from improved access. Improving access to CGM has been the

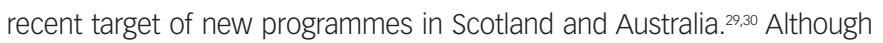
these programmes are not yet mature enough to be assessed, patients and patient advocacy organisations welcomed these developments. Yet the future of CGM utilisation in the UK continues to be uncertain.

Although current clinical guidelines from the UK National Institute for Health and Care Excellence (NICE) recommend use of CGM in specific situations (Table 1), there is no mandate that funding must be provided, even if a patient meets the NICE clinical criteria for CGM. NICE believes that the evidence demonstrating the efficacy and cost-effectiveness of CGM use is insufficient to recommend routine use of CGM in either adults or children with T1D. ${ }^{31,32}$

Our understanding of the potential benefit of CGM in the UK is limited, as reliable data about the actual incidence of CGM use in the UK are scarce. To address this information deficit, in late 2016 Dexcom commissioned the Nielsen Company to conduct an online survey of a representative sample of current CGM users in England, Scotland and Wales. We report findings from the survey and present a rationale for expanding access to CGM within the UK T1D population. Our goal is to help individuals with diabetes obtain access to the tools they need to more effectively manage their diabetes.

\section{Online survey of continuous glucose monitoring use in the UK \\ Design}

The 29-item online survey was conducted between 29 December 2016 and 25 January 2017. Patients with T1D or caregivers of children with T1D (aged $<18$ years) were recruited from mailing lists, using Nielsen and Harris Polling databases.

The objectives were to: assess respondents' satisfaction and goals with using rtCGM; evaluate the support they receive from their diabetes care team; elucidate the impact of their funding source on overall CGM usage; and to identify inequalities among CGM users versus the general UK population.

\section{Respondents}

A total of 315 patients and patient caregivers across the UK responded to the survey: Scotland $(n=25)$, Northern England $(n=70)$, Midlands/Eastern England $(n=65)$, London $(n=86)$, Southern England $(n=56)$ and Wales $(n=13)$. Among the respondents were 170 patients aged $\geq 18$ and 145 caregivers of patients with T1D aged $<18$.

Average duration of CGM usage was 3 years. Slightly more respondents reported treatment with insulin pump therapy $(n=178)$ compared with MDI $(n=137)$. Almost half of all respondents received full National Health Service (NHS) funding for their CGM device $(n=144)$ regardless of their method of insulin delivery (Table 2). More respondents ( $n=232,73.7 \%$ ) used a Dexcom CGM system (G4 or G5) (Dexcom, San Diego, CA, US) than a Medtronic Enlite ${ }^{\circledR}$ CGM system (Medtronic, Northridge, CA, US) $(n=82$, 26.0\%); one respondent reported use of another system, which was not identified. Users of the FreeStyle Libre ${ }^{\mathrm{TM}}$ Flash Glucose Monitoring system (Abbott Diabetes Care, Alameda, CA, US) were excluded from the survey, as this device does not offer alerts/alarms as recommended by NICE guidelines.
Figure 1: Comparison of glycaemic control by country/registry

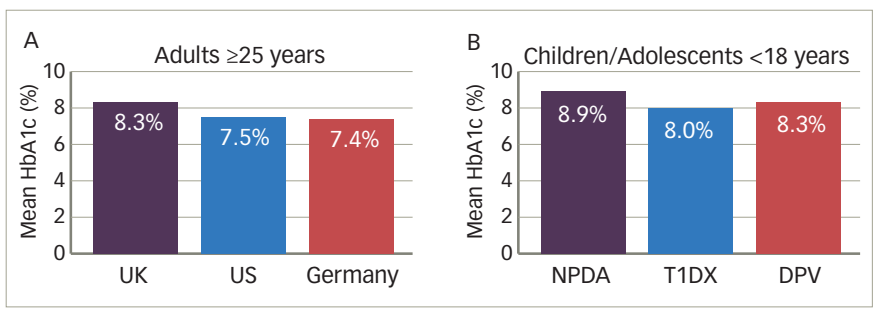

HDA1C = glycated haemoglobin; NPDA = UK National Paediatric Diabetes Audit; T1DX = US Type 1 Diabetes Exchange; DPV = Austrian/German Prospective Diabetes Follow-up Registry.

Table 1: National Institute for Health and Care Excellence diabetes clinical guidelines - excerpts ${ }^{31,32}$

\section{Continuous glucose monitoring: adults}

1.6.21 Do not offer real-time continuous glucose monitoring routinely to adults with type 1 diabetes. [new 2015]

1.6.22 Consider real-time continuous glucose monitoring for adults with type 1 diabetes who are willing to commit to using it at least $70 \%$ of the time and to calibrate it as needed, and who have any of the following despite optimised use of insulin therapy and conventional blood glucose monitoring:

- More than one episode a year of severe hypoglycaemia with no obviously preventable precipitating cause.

- Complete loss of awareness of hypoglycaemia.

- Frequent (more than two episodes a week) asymptomatic hypoglycaemia that is causing problems with daily activities.

- Extreme fear of hypoglycaemia.

- Hyperglycaemia (HbA1c level of $75 \mathrm{mmol} / \mathrm{mol}$ [9\%] or higher) that persists despite testing at least 10 times a day (see recommendations 1.6.11 and 1.6.12). Continue real-time continuous glucose monitoring only if $\mathrm{HbA} 1 \mathrm{C}$ can be sustained at or below $53 \mathrm{mmol} / \mathrm{mol}(7 \%)$ and/or there has been a fall in $\mathrm{HbA} 1 \mathrm{c}$ of $27 \mathrm{mmol} / \mathrm{mol}$ (2.5\%) or more. [new 2015]

1.6.23 For adults with type 1 diabetes who are having real-time continuous glucose monitoring, use the principles of flexible insulin therapy with either a multiple daily injection insulin regimen or continuous subcutaneous insulin infusion (CSII or insulin pump) therapy. [new 2015]

1.6.24 Real-time continuous glucose monitoring should be provided by a centre with expertise in its use, as part of strategies to optimise a person's HbA1C levels and reduce the frequency of hypoglycaemic episodes. [new 2015]

\section{Continuous glucose monitoring: children/adolescents}

1.2.62 Offer ongoing real-time continuous glucose monitoring with alarms to children and young people with type 1 diabetes who have:

- frequent severe hypoglycaemia or

- impaired awareness of hypoglycaemia associated with adverse consequences (for example, seizures or anxiety) or

- inability to recognise, or communicate about, symptoms of hypoglycaemia (for example, because of cognitive or neurological disabilities). [new 2015]

1.2.63 Consider ongoing real-time continuous glucose monitoring for:

- neonates, infants and pre-school children

- children and young people who undertake high levels of physical activity (for example, sport at a regional, national or international level)

- children and young people who have comorbidities (for example anorexia nervosa) or who are receiving treatments (for example corticosteroids) that can make blood glucose control difficult. [new 2015]

1.2.64 Consider intermittent (real-time or retrospective) continuous glucose monitoring to help improve blood glucose control in children and young people who continue to have hyperglycaemia despite insulin adjustment and additiona support. [new 2015]

HDA1C = glycated haemog/obin. Sources: National Institute for Health and Care Excellence (NICE), $2015^{31}$ and National Institute for Health and Care Excellence (NICE), 2015. ${ }^{32}$ 
Table 2: Continuous glucose monitoring funding source by insulin delivery method

\begin{tabular}{|l|l|l|}
\hline & $n$ & $\%$ Respondents \\
\hline Pump & 178 & \\
\hline $100 \%$ NHS funded & 81 & $45.51 \%$ \\
\hline $100 \%$ self funded & 54 & $30.34 \%$ \\
\hline Partial funding & 34 & $19.10 \%$ \\
\hline Miscellaneous & 9 & $5.06 \%$ \\
\hline MDI & 137 & \\
\hline $100 \%$ NHS funded & 63 & $45.99 \%$ \\
\hline $100 \%$ self funded & 29 & $21.17 \%$ \\
\hline Partial funding & 38 & $27.74 \%$ \\
\hline Miscellaneous & 7 & $5.11 \%$ \\
\hline Total & 315 & \\
\hline
\end{tabular}

MDI = multiple daily insulin injections; NHS = National Health Service.

\section{Statistical analysis}

The mean CGM usage (\% time) was calculated for the various subgroups in the survey. Where usage was a continuous variable (i.e., mean usage), comparisons were made using an analysis of variance (ANOVA), or using a t-test when the number of groups was equal to 2 . Frequency tables were generated and the proportions of factor levels were tested using Chi-squared and Fisher's exact tests.

\section{Findings}

\section{Perceived value of continuous glucose monitoring}

As shown in Table 3, the majority of patients and caregivers felt that their key expectations of CGM were mostly realised. Most respondents reported improvements in HbA1C, fewer hypoglycaemia episodes, improved hypoglycaemia awareness and better overall management of their diabetes. Importantly, the majority of respondents reported that the value of CGM outweighs the cost. There were no statistically significant differences in the perceived value of CGM among respondents, regardless of funding source.

\section{Continuous glucose monitoring usage}

Average CGM usage was found to vary by funding source, method of insulin delivery and brand of CGM device (Table 4). Self-funders reported using their CGM $76.1 \%$ of days per month. This was significantly higher ( $p=0.0008)$ than those who were fully funded $(58.9 \%)$ and/or partially funded. The percentage of usage was significantly higher among insulin pump users compared with MDI-treated respondents. The proportion of CGM usage time was significantly higher among Dexcom CGM users compared with Medtronic CGM users.

A significantly higher percentage of Dexcom CGM users (62.1\%) reported wearing their device $>70 \%$ of the time compared with Medtronic CGM users (37.8\%), $p=0.0001$. Among respondents treated with insulin pump therapy, the percentage of CGM usage ( $>70 \%$ of the time) was significantly higher among Dexcom users (77.7\%) compared with Medtronic users (53.9\%), $p<0.0001$. A similar difference in percentage of CGM usage was observed in Dexcom versus Medtronic users treated with MDI: 61.2\% versus $50.2 \%$, respectively, $\mathrm{p}=0.09$.

\section{Diabetes team support}

A funding effect was observed in respondents' perceptions of the support they receive from the diabetes care team. A significantly higher percentage of fully funded (94.4\%) and partially funded (91.7\%) respondents indicated
Table 3: Perceptions of continuous glucose monitoring value

\begin{tabular}{|l|l|l|}
\hline Item & $\mathrm{n}$ & $\%$ Respondents \\
\hline Key expectations met & 251 & $79.7 \%$ \\
\hline Improved HbA1C & 211 & $67.0 \%$ \\
\hline Fewer hypoglycaemia episodes & 221 & $70.2 \%$ \\
\hline Improved hypoglycaemia awareness & 244 & $77.5 \%$ \\
\hline Better overall diabetes management & 291 & $92.4 \%$ \\
\hline CGM value outweighs cost & 272 & $86.4 \%$ \\
\hline
\end{tabular}

$C G M=$ continuous g/ucose monitoring; $H D A 1 C=$ glycated haemoglobin .

Table 4: Continuous glucose monitoring usage (\% wear)

\begin{tabular}{|l|l|l|}
\hline By funding source & $\mathrm{n}$ & $\%$ days/month \\
\hline $100 \%$ NHS funded & 144 & $58.9 \%$ \\
\hline $100 \%$ self funded & 83 & $76.1 \%$ \\
\hline Partial funded & 72 & $65.9 \%$ \\
\hline By insulin delivery method & & \\
\hline Insulin pump & 178 & $70.6 \%$ \\
\hline MDI & 137 & $59.1 \%$ \\
\hline By device brand & & \\
\hline Dexcom & 232 & $70.1 \%$ \\
\hline Medtronic & 82 & $52.6 \%$ \\
\hline
\end{tabular}

Self funded versus fully funded/partially funded, $p=0.0008$; insulin pump versus MDI, $p=0.0025$; Dexcom versus Medtronic, $p<0.0001$. MDI = multiple daily insulin injections; NHS = National Health Service.

satisfaction with their diabetes care team compared with self funded (80.7\%) respondents ( $p=0.0035)$. Approximately $51 \%$ of caregivers reported that their child's diabetes team could be doing more to help them manage their child's diabetes. Confidence in the diabetes care team's advice was significantly higher among fully funded (85.4\%) and partially funded respondents (94.4\%) respondents compared with that among self-funded (71.1\%) respondents $(\mathrm{p}=0.0003)$.

Notable, but not statistically significant differences in diabetes team support regarding CGM use were also observed (Table 5). A smaller percentage of self-funders reported that their team assisted them in interpreting their CGM data on a regular basis compared with fully funded and partially funded respondents. A significantly lower percentage of self funded respondents reported receiving guidance in how to use their CGM devices compared with fully funded and partially funded respondents. A significantly higher percentage of self-funders reported receiving no CGM support from their diabetes team compared with fully funded and partially funded respondents.

\section{Funding assistance}

Only 23 (27.7\%) self-funders reported that their team applied for CGM funding. Among the 57 self-funders who requested that their team apply for funding, $23(41.8 \%)$ reported that their team was unwilling to apply; 15 (27.3\%) were told they were ineligible for funding, 15 (27.3\%) were told that there is no NHS funding available and four (7.3\%) reported that their team never provided a reason for not applying for funding.

\section{Discussion}

This is the first survey to assess whether and how T1D patients and caregivers are benefitting from CGM in the UK. The survey results suggest that UK patients are realising tangible benefits from their CGM use, which are similar to those seen in other countries. Most of those 
surveyed agree that CGM use increases confidence, enables better management of diabetes, greatly improves quality of life, and that the value outweighs the cost. However, our findings indicate that the level of support received by patients and caregivers using CGM in the UK is suboptimal. Approximately half of all respondents indicated that their diabetes care team could be doing more to help manage diabetes; approximately 40\% feel they do not get enough support in using CGM. Moreover, self-funders are less likely to: be satisfied with their diabetes care team relationship; feel their team understands their needs; and feel confident in the team's advice. These views of their diabetes care teams stand in contrast to their reported belief that CGM technology is helping them improve their diabetes control. These data also suggest that only half of the people using CGM are getting support with interpretation and disease management even when their CGM is fully funded.

An interesting finding was the notable difference in both preference and frequency of use between the Dexcom and Medtronic CGM systems. Despite greater accuracy and reliability among all current CGM systems, differences in performance between the current manufacturers remain. These differences can influence frequency of use and user perceptions of accuracy and utility.

Polonsky and Hessler reported that satisfaction with device performance was an independent predictor of perceived control over diabetes and hypoglycaemia. ${ }^{35}$ The same data set showed that satisfaction with performance was also associated with more frequent CGM use, perceptions of device usefulness in avoiding hypoglycaemia and hyperglycaemia and in achieving better overall glycaemic control. ${ }^{36}$ In 2013, Chamberlain et al. reported results from a survey of 87 CGM users ( $n=40$, Dexcom; $n=47$ Medtronic) to explore whether their frequency of sensor use was related to CGM technology, in general, or to differences among currently available CGM systems. ${ }^{37}$ Survey results showed that $76 \%$ of Dexcom users reported wearing their devices 'almost daily', compared with $19 \%$ of Medtronic users. Differences in the accuracy of the CGM systems used by respondents in our survey may explain the differences in preference and frequency of use.

Although diabetes outcomes measures can be influenced by several factors, significant discrepancies exist in glycaemic control between the UK and other countries (Figure 1). However, the survey findings demonstrate marked inequalities within the UK in terms of who receives funding for CGM and the support they receive from their diabetes care team. For example, although approximately $40 \%$ of the UK population has an annual household income of $<£ 25,000,33,38$ only $19 \%$ of survey respondents reported income in this bracket. Additionally, whereas $60 \%$ of respondents reported having a university-level education, only approximately $41 \%$ of adults in the UK have earned a tertiary qualification. ${ }^{39}$ Because the survey included a representative sample of the UK population, the income and educational disparities between survey respondents and the general public suggest that access to CGM use may be disproportionately greater among those with higher income and better education. However, these disparities may only partially explain the relatively low adoption of CGM in the UK; geographic location may also play a major role in access.

In 2013, the NHS replaced Primary Care Trusts (PCTS) with Clinical Commissioning Groups (CCGs), which are responsible for the planning
Table 5: Diabetes care team support for continuous glucose monitoring use

\begin{tabular}{|l|l|l|l|l|l|}
\hline \multirow{2}{*}{ Assistance } & \multicolumn{4}{l}{ Funding (\% respondents) } & p-value \\
\cline { 2 - 5 } & Full & Partial & Self & \\
\hline Interpreting CGM data & 46.5 & 51.4 & 42.2 & 0.5174 \\
\hline Guidance in using CGM device & 44.4 & 58.3 & 19.3 & $<0.0001$ \\
\hline No CGM support from team & 2.8 & 1.4 & 30.1 & $<0.0001$ \\
\hline
\end{tabular}

CGM = continuous g/ucose monitoring.

and commissioning of healthcare services for their local area. While some CCGs have pioneered pathways for CGM access, ${ }^{40}$ others have not. Regardless of their clinical need, a patient's diabetes care team cannot access CGM funding if the patient's local CCG considers them ineligible. This situation is often referred to as 'postcode prescribing'. This may explain why over 30\% of survey respondents who have insulin pump funding must self fund their CGM use (Table 2).

Another important finding from the survey is the lack of support for patients regarding CGM use, which suggests that the current lack of a coherent CGM funding policy in the UK has conditioned healthcare providers' willingness and ability, to assist patients in obtaining funding and provide clinical assistance to CGM users. As reported, a large percentage of respondents stated they receive little or no support in interpreting and utilising their CGM data, especially self-funders, who are motivated to optimise their diabetes control. Moreover, the notable percentage of respondents who reported that their diabetes care team refused to apply for funding may reflect a lack of awareness of the pathways that exist and/or an inability to identify patients who could benefit from CGM use.

Self-selection of respondents may be considered a limitation of our survey. However, because participants were recruited from the Nielsen databases, we believe bias was likely minimal. Additionally, although the sample size $(n=315)$ was robust, it likely represents only a small portion of CGM users in the UK. Nevertheless, this is the first survey to query CGM users about their perceptions, response to treatment and challenges in obtaining support from their diabetes care team, drawing upon the experience of both caregivers of T1D children/adolescents and adult CGM users across the UK.

The current situation regarding CGM funding and support in the UK in some ways parallels the experiences of many patients who tried to obtain funding for an insulin pump prior to the first NICE Technology Appraisal on insulin pump therapy. ${ }^{41}$ As reported earlier by White and colleagues, ${ }^{42}$ the prevalence of insulin pump use in the UK remains below the expectation of NICE and usage rates of other Western countries, and this may be due, in part, to lack of adequate training among healthcare providers.

The NHS was created out of the ideal that 'good healthcare should be available to all, regardless of wealth'. ${ }^{43}$ It has faced many challenges since its inception in 1948 and the current difficulties in accessing diabetes technology represent one more barrier to be addressed. Changes in training, attitude and prioritisation of healthcare resources are needed. Continuing to restrict and deny patient access to CGM and the support to use it optimally is both detrimental to patients and 'unhealthy' for the healthcare system. $\square$ 
1. Diabetes Control and Complications Trial Study Group, The effect of intensive treatment of diabetes on the development and progression of long-term complications in insulindependent diabetes mellitus, N Engl J Med, 1993;329:977-86.

2. Diabetes Control and Complications Trial/Epidemiology of Diabetes Interventions and Complications Study Research Group, Intensive diabetes treatment and cardiovascular Group, Intensive diabetes treatment and cardiovascular outcomes in type 1 diabetes: The DCCT/EDI
follow-up, Diabetes Care, 2016:39:686-93.

3. McKnight JA, Wild SH, Lamb MJ, et al., Glycaemic control of Type 1 diabetes in clinical practice early in the 21st century: an international comparison, Diabet Med, 2015;32:1036-50.

4. Calvert M, Shankar A, McManus RJ, et al., Effect of the quality and outcomes framework on diabetes care in the United Kingdom: retrospective cohort study, BMJ, 2009;338:b1870.

5. Sherr JL, Hermann JM, Campbell F, et al., Use of insulin pump therapy in children and adolescents with type 1 diabetes and its impact on metabolic control: comparison of results from three large, transatlantic paediatric registries, Diabetologia 2016:59:87-91.

6. Battelino T, Conget I, Olsen B, et al., The use and efficacy of continuous glucose monitoring in type 1 diabetes treated continuous glucose monitoring in type 1 diabetes treated
with insulin pump therapy: a randomised controlled trial, Diabetologia, 2012:55:3155-62.

7. Hommel E, Olsen B, Battelino T, et al., Impact of continuous glucose monitoring on quality of life, treatment satisfaction, and use of medical care resources: analyses from the SWITCH study, Acta Diabetol, 2014;51:845-51.

8. Picard S, Hanaire H, Baillot-Rudoni S, et al., Evaluation of the adherence to continuous glucose monitoring in the management of type 1 diabetes patients on sensor-augmented pump therapy: the SENLOCOR Study, Diabetes Technol Ther 2016; 18:127-35.

9. Choudhary P, Olsen BS, Conget I, et al., Hypoglycemia prevention and user acceptance of an insulin pump system with predictive low glucose management, Diabetes Techno Ther, 2016:18:288-91.

10. Esvant A, Lefebvre MA, Campillo-Gimenez B, et al., A mobile application guiding patients with type 1 diabetes using sensoraugmented insulin pump therapy, J Diabetes Sci Technol, 2016;28;10:985-6.

11. Triolo TM, Maahs DM, Pyle $L$, et al., Effects of frequency of sensor-augmented pump use on hba1c and c-peptide levels in the first year of type 1 diabetes, Diabetes Care, 2016;39:e61-2.

12. Juvenile Diabetes Research Foundation Continuous Glucose Monitoring Study Group, Effectiveness of continuous glucose monitoring in a clinical care environment: evidence from the Juvenile Diabetes Research Foundation continuous glucose monitoring (JDRF-CGM) trial, Diabetes Care, 2010;33:17-22.

13. New JP, Ajjan R, Pfeiffer AF, Freckmann G, Continuous glucose monitoring in people with diabetes: the randomized controlled Glucose Level Awareness in Diabetes Study (GLADIS), Diabet Med, 2015:32:609-17.

14. Wong JC, Foster NC, Maahs DM, et al., Real-time continuous glucose monitoring among participants in the T1D Exchange glucose monitoring among participants in the
clinic registry Diabetes Care, 2014:37:2702-9.

15. Riveline JP, Schaepelynck P, Chaillous L, et al., Assessment of patient-led or physician-driven continuous glucose monitoring in patients with poorly controlled type 1 diabetes using basalbolus insulin regimens: a 1-year multicenter study, Diabetes Care, 2012;35:965-71.

16. Rachmiel M, Landau Z, Boaz M, et al., The use of continuous glucose monitoring systems in a pediatric population with type 1 diabetes mellitus in real-life settings: the AWeSoMe Study

Group experience, Acta Diabetol, 2015;52:323-9.

Konoff DC, Garg SK, et al., Threshold-based nsulin-pump interruption for reduction of hypoglycemia, N Engl Med, 2013;369:224-32.

18. Weinstock RS, Xing D, Maahs DM, et al., Severe hypoglycemia and diabetic ketoacidosis in adults with type 1 diabetes: results from the T1D Exchange clinic registry, J Clin Endocrinol Metab, 2013;98:3411-9.

19. Pickup JC, Freeman SC, Sutton AJ, Glycaemic control in type 1 diabetes during real time continuous glucose monitoring compared with self monitoring of blood glucose: meta-analysis of randomised controlled trials using individual patient data, BMJ, 2011;343:d3805

20. Garg SK, Voelmle MK, Beatson CR, et al., Use of continuous glucose monitoring in subjects with type 1 diabetes on multiple daily injections versus continuous subcutaneous insulin infusion therapy: a prospective 6-month study, Diabetes Care, 2011:34:574-9.

21. Beck RW, Riddlesworth T, Ruedy K, et al., Effect of continuous glucose monitoring on glycemic control in adults with type 1 diabetes using insulin injections: the DIAMOND randomized clinical trial, JAMA, 2017:317:371-8.

22. Ruedy KJ, Parkin CG, Riddlesworth TD, Graham C, Diamond Study Group, Continuous glucose monitoring in older adults with type 1 and type 2 diabetes using multiple daily injections of insulin: results from the DIAMOND Trial, J Diabetes SC Technol, 2017:1932296817704445.

23. Lind M, Polonsky W, Hirsch IB, et al., Continuous glucose monitoring vs conventional therapy for glycemic contro in adults with type 1 diabetes treated with multiple daily insulin injections: the GOLD randomized clinical trial, JAMA 2017;317:379-87.

24. Aleppo G, Ruedy KJ, Riddlesworth TD, et al., REPLACE-BG: a randomized trial comparing continuous glucose monitoring with and without routine blood glucose monitoring in adults with well-controlled type 1 diabetes, Diabetes Care, adults with well-cont

25. Tumminia A, Crimi S, Sciacca L, et al., Efficacy of real-time continuous glucose monitoring on glycaemic control and glucose variability in type 1 diabetic patients treated with either insulin pumps or multiple insulin injection therapy: a randomized controlled crossover trial, Diabetes Metab Res Rev, 2015;31:61-8.

26. Parkin CG, Graham C, Smolskis J, Continuous glucose monitoring use in type 1 diabetes: Iongitudinal analysis demonstrates meaningful improvements in $\mathrm{HDA} 1 \mathrm{C}$ and reductions in health care utilization, J Diab Sci Techn, 2017:11:522-8.

27. Walsh J, Roberts $R$, Weber $D$, et al., Insulin pump and CGM usage in the United States and Germany: results of a real-world survey with 985 subjects, I Diabetes Sci Technol, 2015;9:1103-10.

28. Joint Federal Committee, Contract care: continuous interstitia glucose measurement With real-time measuring devices (rtCGM) - therapy control in patients and patients with insulin-dependent diabetes mellitus. Available at: www. bauchspeicheldruese-pankreas-selbsthilfe.de/download/ pdf/kontinuirliche-blutzuckermessung-rtCGM-beschluss.pd (accessed 22 June 2017).

29. Diabetes UK, Diabetes Scotland calls for better and fairer access to diabetes technology, March 2017. Available at:
www.diabetes.org.uk/In_Your_Area/Scotland/news/DiabetesScotland-calls-for-better-and-fairer-access-to-diabetestechnology/ (accessed 27 June 2017).

30. Australian Government - Department of Health, Australian government subsidy of continuous glucose monitors, June 2017. Available at: www.health.gov.au/internet/main/ publishing.nsf/Content/MC15-004873-continuous-glucosemonitors (accessed 27 June 2017).

31. National Institute for Health and Care Excellence (NICE), Type 1 diabetes in adults: diagnosis and management, NICE guideline [NG17], last updated July 2016, London, UK: National Institute for Health and Care Excellence, 2015. Available at: www.nice. org.uk/guidance/NG17 (accessed 4 May 2017).

32. National Institute for Health and Care Excellence (NICE), Diabetes (type 1 and type 2) in children and young people: diagnosis and management. Guidelines [NG18], last updated November 2016, London, UK: National Institute for Health and Care Excellence, 2015. Available at: www.nice.org uk/guidance/ NG18 (accessed 4 May 2017).

33. Bailey TS, Ahmann A, Brazg R, et al., Accuracy and acceptability of the 6-day Enlite continuous subcutaneous glucose sensor, Diabetes Technol Ther, 2014:16:277-83.

34. Bailey TS, Chang A, Christiansen M, Clinical accuracy of a continuous glucose monitoring system with an ad algorithm, J Diabetes Sci Technol, 2015,9:209-14.

35. Hessler D, Polonsky WH, Bowman F, Price D, The subjective experience of CGM-RT use: Comparing current users with exusers, Diabetes, 2012;61(Suppl 1):A215.

36. Polonsky WH, Hessler D, Perceived accuracy in continuous glucose monitoring: understanding the impact on patients, $J$ Diabetes Sci Technol, 2015;9:339-41.

37. Chamberlain J, Dopita D, Gilgen E, Persistence of continuous glucose monitoring use in a community setting 1 year after purchase, Clin Diabetes, 2013;31:106-9.

38. Office for National Statistics, Gross household income by income decile group, UK, financial year ending 2016 Available at: www.ons.gov.uk/peoplepopulationandcommunity/ personalandhouseholdfinances/expenditure/adhocs/ 006770grosshouseholdincomebyincomedecilegroupukfinancial yearending2016 (accessed 24 June 2017).

39. Organisation for Economic Co-operation and Development (OECD), Education at a glance: OECD indicators/United Kingdom. Available at: www.oecd.org/unitedkingdom/United Kingdom-EAG2014-Country-Note.pdf (accessed 23 June 2017).

40. Northwest London Commissioning Collaborative Groups, Policy Position Statement - continuous glucose monitoring devices (CGM) for type 1 iabetes (adults only), November 2016. Available at: www.hounslowccg.nhs.uk/media/79732/CGMfor-Type-1-Diabetes-Position-Statement-November-2016.pdf (accessed 22 June 2017)

41. National Institute for Health and Care Excellence (NICE), Continuous subcutaneous insulin infusion for the treatment of diabetes mellitus: Technology appraisal guidance [TA151] July 2008. Available at: www.nice.org uk/guidance/ta151/chapter/2 Clinical-need-and-practice (accessed 23 June 2017).

42. White HD, Goenka N, Furlong NJ, et al., The U.K. service level audit of insulin pump therapy in adults, Diabet Med, 2014;31:412-8.

43. National Health Service (NHS), About the NHS: Principles and values that guide the NHS. Available at: www.nhs.uk/ NHSEngland/thenhs/about/Pages/nhscoreprinciples.aspx (accessed 23 June 2017) 